Article

\title{
In/Visibility in Social Media Work: The Hidden Labor Behind the Brands
}

\author{
Brooke Erin Duffy * and Megan Sawey \\ Department of Communication, Cornell University, USA \\ * Corresponding author (bduffy@cornell.edu)
}

Submitted: 30 April 2021 | Accepted: 12 July 2021 | Published: 20 January 2022

\begin{abstract}
Despite the staggering uptick in social media employment over the last decade, this nascent category of cultural labor remains comparatively under-theorized. In this article, we contend that social media work is configured by a visibility paradox: While workers are tasked with elevating the presence-or visibility-of their employers' brands across Facebook, Twitter, Instagram, and more, their identities, and much of their labor, remain hidden behind branded social media accounts. To illuminate how this ostensible paradox impacts laborers' conditions and experiences of work, we present data from in-depth interviews with more than 40 social media professionals. Their accounts make clear that social media work is not just materially concealed, but rendered socially invisible through its lack of crediting, marginal status, and incessant demands for un/under-compensated emotional labor. This patterned devaluation of social media employment can, we show, be situated along two gender-coded axes that have long structured the value of labor in the media and cultural industries: a) technical-communication and b) creation-circulation. After detailing these in/visibility mechanisms, we conclude by addressing the implications of our findings for the politics and subjectivities of work in the digital media economy.
\end{abstract}

\section{Keywords}

cultural production; digital media; gender; invisibility; labor; social media; technology; work

\section{Issue}

This article is part of the issue "New Forms of Media Work and Its Organizational and Institutional Conditions" edited by Salla-Maaria Laaksonen (University of Helsinki) and Mikko Villi (University of Jyväskylä).

(C) 2022 by the author(s); licensee Cogitatio (Lisbon, Portugal). This article is licensed under a Creative Commons Attribution 4.0 International License (CC BY).

\section{Introduction}

Though "going viral" on social media is-at best-a lofty ambition, the internet is rife with pseudo-experimental "hacks" and "tricks" assuring individuals and businesses that they can garner likes, comments, shares, and other markers of reputational currency. Yet, as a report in the online trade publication Digiday headlined, "things don't go viral by themselves" (Chen, 2016, para. 3). Rather, social media success owes much to the concerted efforts of a relatively new sub-category of digital laborers: social media managers. In chronicling these socalled "cabals" of social media professionals, the Digiday report helped draw attention to the invisible laborers powering the accounts of major media and marketing brands. Indeed, storied news organizations, buzzy clothing retailers, renowned educational institutions, and major media publishers all enlist trained professionals to manage their companies' social media presence. Though their job titles range-common position designators include social media managers, editors, audience development coordinators, and community managerswhat we collectively refer to as "social media workers" are positioned at the interface of creativity and technology in the digital media economy. In addition to creating and circulating branded content across Facebook, Twitter, Instagram, and more, social media workers are responsible for fielding comments and messages from consumer-audiences; boosting their companies' likes, follower counts, and conversion rates; and monitoring and evaluating analytic data. In short, their work hinges on the logic of visibility.

But, crucially, social media workers' earnest pursuit of visibility on behalf of their employers-whereby 
they represent "the frontline of brands" (Webb, 2020)belies the fact that their own identities are hidden behind these branded social media accounts. To be sure, both popular articles and academic writings (e.g., Duffy \& Schwartz, 2018; McCosker, 2017) have noted the patterned concealment of the editors and managers who run branded social media accounts. In 2015, for instance, journalist Alana Hope Levinson (2015) suggested that the women-dominated makeup of social media-along with employers' tendency to diminish the significance of these roles-heralded a new "pink ghetto" of media organizations. In a nod toward the wider cultural devaluation of women's work, "invisibility" and lack of crediting were persistent themes in Levinson's exposition. Other accounts of the professional field have also invoked hidden worker subjectivities: Social media workers have thus been described as the people "behind the brand account" (Troughton, 2021), the "unseen face behind a brand" (Uifalean, 2019), and those "behind the screen" (Spencer, 2017). Such invisibility marks a critical departure from other conceptualizations of social media in the domains of work and labor. In contrast to those individuals who deploy social media for work-namely the carefully curated "identity work" that structures the production of a visible self-brand-those for whom social media is work are largely concealed to various publics (for a discussion of the intersections of social media and work, see Bagger, 2021).

Accordingly, we contend that social media work is configured by a visibility paradox: While workers are tasked with elevating the reputation and presenceor visibility-of their respective organizations across Facebook, Twitter, TikTok, YouTube, and Instagram, their efforts to do so are invisible, concealed as they are in the background of branded accounts. Although social media is by no means the only site of such a paradox (see, for example, Anteby \& Chan's 2018 work on surveillance, and Mateescu \& Ticona's 2020 account of "visibility regimes"), we argue that this employment field is analytically rich given both its recency and its divergence from many other categories of digital labor defined exclusively through their hidden status (e.g., Crain et al., 2016; Hatton, 2017; Jarrett, 2016; van Doorn, 2017). Gray and Suri (2019), for instance, describe how the piecemeal labor force propelling Big Tech relies upon a global army of "ghost workers": people who complete myriad projectbased assignments, often without recognition via bylines or full-time salaries (see also, Irani, 2015). Studies of online content moderators, too, contend that the invisibility of social media's digital "cleaners" is baked into platforms' design; the labor of content moderation is thus "largely imperceptible to the users of the platforms who pay for and rely upon this labor" (Roberts, 2019, p. 3; see also, Gillespie, 2018, p. 114). Offering a broader perspective on the invisibility of various modes of virtual work, Cherry (2016) details how new technologies are "transforming the foundations of where, when, and how work is performed... in the process obscur[ing] the worker from the view of the Web site users or ultimate consumer" (pp. 12-13). But while task-work and content moderation are about the production of invisibility, the aim of social media management is precisely the opposite. Examining workers' understandings of and experiences with this visibility-invisibility tension can, we argue, tell us much about the valuation of work in the digital media economy.

In this article, we present data from in-depth interviews with more than 40 social media professionals to illuminate how this seeming visibility paradox shapes laborers' conditions and experiences of work. Accounts from our interviews indicate that social media work is not only intentionally hidden by the workers themselves (Weidhaas, 2017); rather, the labor is rendered socially and economically invisible-that is, devalued-through a lack of crediting, marginal status, and the felt obligation to provide various forms of un/under-compensated emotional labor. As we show, moreover, our participants tended to frame such valuations-both their own and the perceptions of value expressed by employers and the public-along two axes that have long structured the organization and status of labor in the media and cultural industries: a) technical-communication and b) creationcirculation. These axes have historically invoked a gendered division of labor that prioritizes masculine-coded technical skills and creation at the expense of feminized communication and publicity/promotional roles (see, for example, Lipartito, 1994; Mayer, 2014). Accordingly, discursive placement on the latter poles of these parallel axes-be it from employers, colleagues, or members of the public-functioned much like the socio-cultural "mechanisms of invisibility" detailed by Hatton (2017), wherein "labor is [economically] devalued by virtue of hegemonic cultural ideologies" (p. 337). After examining how workers interpreted-and at times, challengedthese in/visibility mechanisms, we conclude by addressing the implications of these findings for the wider politics and valuation of digital media work.

\section{Background and Context}

\subsection{Invisible Labor in the Media and Cultural Industries}

In the three-plus decades since sociologist Arlene Kaplan Daniels (1987) theorized that contemporary social institutions devalue women's social and reproductive labor by making their work symbolically "disappear," the concept of invisibility has gained considerable traction in scholarship on work, labor, and employment (e.g., Crain et al., 2016; Hatton, 2017; Star \& Strauss, 1999; van Doorn, 2017). Indeed, the designation "invisible" has been applied to an astonishingly diverse array of activities - both waged and unwaged-spanning healthcare, childcare, and other forms of care work (Armstrong et al., 2008; Ticona \& Mateescu, 2018); service-based sectors which emphasize feminized, emotional performances and the provision of "soft skills" (e.g., Hochschild, 
1983/2012; Poster, 2016); aesthetic work and hidden bodily labor (Hatton, 2017; Mears, 2014); and various kinds of computer-mediated work, including the hazily defined category of "digital labor" (e.g., Irani, 2015; Jarrett, 2016; Sannon \& Cosley, 2019). The wide-ranging uptake of "invisible labor" across disciplines and career sectors is, according to Hatton (2017), "due, at least in part, to [the concept's] success in drawing attention to those types of labor that have been overlooked in popular and scholarly accounts of work and employment" (p. 337).

There is a tendency in many of the aforementioned works to equate the relative in/visibility of a worker or task with the latter's economic valuation; invisible work is, in other words, largely un/under-compensated. Of course, visibility also functions as a proxy for other systems of value exchange, including social status/esteem (Abidin, 2016; Duffy, 2017); contribution to consumer capitalism (Budd, 2016), and/or recognition within a regulatory/institutional system (Crain et al., 2016; Ticona \& Mateescu, 2018). To the latter, Crain et al. (2016, p. 6) define invisible labor as the activities:

Workers perform in response to requirements (either implicit or explicit) from employers and that are crucial for workers to generate income, to obtain or retain their jobs, and to further their careers, yet are often overlooked, ignored, and/or devalued by employers, consumers, workers, and ultimately the legal system itself.

While Crain et al.'s (2016) placement of "workers" alongside external factions like employers and the legal system may seem contradictory, it testifies to an important distinction between invisible labor and hidden work: whereas the former comprises activities that are discredited by external social actors (under a normative assumption that the worker desires visibility), the latter refers to those acts internally concealed by the workers themselves (Weidhaas, 2017). Weidhaas's (2017) distinction is especially relevant for the present study given that social media workers are, by definition, required to "hide" their personae behind the accounts of major media and marketing brands.

Perhaps not surprisingly, many accounts of invisible work and labor note how visibility ideals and valuations are deeply imbricated with social identity politics. Duffy's (2007) conception of "dirty work," for instance, illustrates how categories of work associated with marginalized groups-including the cleaning and care work disproportionally shouldered by women and people of color-are rendered invisible through their stigmatized placement in the capitalist economy (see also, Mateescu \& Ticona, 2020). Meanwhile, one of the key "mechanisms of invisibility" that Hatton (2017) developsnamely socio-cultural-calls attention to the patterned devaluation of work embedded within "hegemonic ideologies of gender, race, class, age and ability" (p. 338).
In explicating the role of identity in these various occupational denigrations, these scholars denaturalize crass assumptions between the complexity of the work and its economic and/or social status. As Webster (2014) usefully reminds to this end, the devaluation of tasks associated with marginalized groups occurs "no matter how much individual jobs may involve competence, skill, and technological knowledge" (p. 143; see also, Mayer, 2014).

Webster's (2014) exposition of "technological knowledge" in the context of "women's work" provides a useful backdrop for understanding how work in the media and cultural industries has been oriented around a gendered division of labor. Histories of telecommunications, computing, film, and journalism reveal how the technical and creational aspects of various professions and roles have been coded as masculine, whereas communications and promotional skills are ascribed to femininized subjectivities (Hill, 2016; Light, 1999; Lipartito, 1994; Mayer, 2014). Lipartito (1994) thus notes how the turn-of-the-last-century telecommunications industry represents "an extreme example of how technology and innovation could contribute to the construction of new female occupations while at the same time confirming old ideas about female work" (p. 1087). The cultural image of the "telephone girl" that circulated during that time helped to mitigate concerns about the technology itself through appeals to feminized notions of trust and community (Mayer, 2014). Tying these gendered prescriptions to notions of invisibility, Mayer (2014) notes that while these positions superficially promised young women class mobility, the work remained "invisible"even to the laborers themselves (p. 51).

The journalism industry has also been structured by a gender-coded division of labor: one that has rendered particular tasks and content categories-those most often associated with women and journalists of color-socially invisible (Nilsson, 2010). We can also see this dynamic in the history of newspaper bylines, which provide credit and therefore convey recognition (or visibility) to the author. Histories of British journalism note how women reporters have been systematically written out of such chronicles. As Gray (2012) contends of the "unsigned articles" written by 19th-century women journalists, such anonymity meant that women failed to receive "credit" for their research and writing; instead, "the male editor, [who was] named, gained the cultural capital" (p. 8). Unfortunately, these structures of invisibility persist in the contemporary field of journalism, where forms of occupational segregation endure (Hesmondhalgh \& Baker, 2015) along with gender- and race-based disparities in bylines ("Male journalists dominate," 2019). Structures of credit seem all the more critical in today's digital media economy, especially, as Arvidsson et al. (2016, p. 252) put it, "the invisible labor of self-branding has become a condition for professional visibility" (see also Gershon, 2017; Hearn, 2010; Jacobson, 2020). 


\subsection{Brands' Pursuit of Social Media Visibility}

While commercial brands have long sought markers of consumer "awareness," "mindshare," and "recollection," both the measurement and indices of these values have shifted markedly over the last several decades. In the context of 20th-century brand goals, marketers sought to increase product sales, improve audience ratings, and cultivate loyal niche audiences (Turow, 1997). However, the rise of the internet-with its oversaturated market for content-ushered in a new transactional marketplace for brands: the attention economy. Writing in the late 1990s, Goldhaber (1997) proposed that heightened attentiveness functioned as a new source of currency; attention thus represents "a form of wealth that puts you in a preferred position to get anything this new economy offers" (para. 44).

In more recent years, against the backdrop of ubiquitous social media platforms, brands are roused to pursue quantifiable markers of attention and visibility. Accordingly, companies that once created and circulated their "brand voice" through newspapers, magazines, radio stations, and other traditional media outlets are now compelled to ratchet up Facebook shares, Instagram likes, and robust communities of Twitter followers. Social media metrics are, in other words, key indices of brand visibility and hence value. As Baym (2013) writes, "metrics are often made visible in the interfaces themselves, where they can serve as proxies for both audience size and engagement, as they stem from active audience choices to click, to follow, to like, to retweet, and so on" (para. 28). Here, it seems useful to call attention to a striking paradox related to the datafication logic that engenders these metrics: social media's mechanisms of datafication are largely "invisible," in part through proprietary mechanisms that are "often inaccessible to public or private scrutiny" (van Dijck \& Poell, 2013, p. 10). Further, the algorithmic systems that undergird social media metrics are largely "inscrutable" to outsiders; such mystique means they carry the persistent "threat of invisibility" (Bucher, 2012).

Though beset by the challenges of "inaccessible" platform infrastructures and "black-boxed" algorithmic systems, visibility remains paramount for brands. As such, most companies employ social media workers of various levels and employment categories (including full-time, part-time, and contract-temporary) to build and manage the former's digital "presence." As McCosker (2017) explains, companies utilize social media "as a matter of influence, analytics and insights, brand and community development or crisis management" (p. 132). Both influence and brand and community development are of particular importance here, as they underscore the demand for visibility. In contrast to those for whom social media is for, about, or instead of work, social media is itself work for these professionals (Bagger, 2021, p. 2034; see also, Jacobson, 2020). However, whereas creators and other social media-enabled workers (e.g., Duffy, 2017; Meisner
\& Ledbetter, 2020; Scolere, 2019) post content that is hitched to their identities, social media workers are expected to remain inconspicuous as they boost the visibility of their brands', rather than their own self-profiles.

While existing studies of social media work (Bagger, 2021; Duffy \& Schwartz, 2018; Jacobson, 2020; McCosker, 2017) provide insight into the emergent category of social media work, the still-nascent status of this profession makes it under-theorized compared to legacy forms of cultural labor. We suggest that examining this employment field through the lens of in/visibility can tell us much about how this work is valued-internally as well as externally. In this article, we examine what it means for social media workers to simultaneously promote branded content and have their personal identity markers-and much of their labor-hidden. Among the questions we address are: How do social media workers understand their profession's conflicting brand visibility and personal anonymity mandates? How might their hidden efforts to direct positive attention toward brands impact their sense of worker value, as well as the value ascribed by external sources (i.e., employers, members of the public)? Do particular "mechanisms of in/visibility" (Hatton, 2017) emerge? Finally, how can theories of visibility and valuation help us understand career categories rendered ever more central to digital capitalism?

\section{Methods}

To address these and other questions about the conditions and experiences of social media work, we draw upon an analysis of 42 in-depth interviews, which were conducted over a span of three years (2017-2019). We recruited interviewees who self-identified as social media professionals on Linkedln, Twitter, Facebook, and/or Instagram; to account for the plethora of job titles held by social media professionals, we employed "social media manager," "social media editor," "audience development coordinator," and related terms as search queries. Given the value of the media and cultural industries as settings for analyzing evolutions in work and labor (Neff, 2012), we focused our attention on workers employed by companies across the news, marketing, fashion, publishing, and retailing sectors. A small subset of interviewees was, however, located outside the cultural industries; this included participants from the culinary arts and higher education.

Interviewees' ages and experience levels ranged considerably; some were college student interns and/or recent graduates, while others had held social media jobs since the early days of Facebook and Myspace. Their employment categorizations varied, too: While most of our interviewees were salaried employees housed within a particular company, several were contract workers who managed social media for various companies at once. Our interviewees were located predominantly in the United States (except for two located in Canada and Europe). Women were over-represented in our sample 
( $n=36$ ) - a trend that reaffirms existing accounts of the feminized nature of social media work (Duffy \& Schwartz, 2018; Levinson, 2015). To protect interviewees' privacy, we assigned each interviewee a pseudonym and removed references to specific employers and identifiable brand strategies.

Interviews, which followed a semi-structured protocol, were conducted one-on-one with one of the authors or a trained research assistant. Most of the interviews took place over the phone or via Skype. We asked about interviewees' educational and employment histories; current positions and organizational structures; personal and professional experiences with social media; interactions with platform metrics and audience members; daily schedules; and perceptions of the skills needed to secure social media jobs. With the interviewees' permission, we recorded the interviews; audio files were subsequently sent to a professional service for anonymous transcription. The authors took a grounded, inductive approach (Glaser \& Strauss, 1967), wherein coding and analysis occurred simultaneously, and codes were used to develop larger categories that guided our framework. As we discuss in the findings section, two prominent tensions emerged from our interview data: those between technical and communication skills and the creation and circulation of cultural products. We deemed these tensions salient given how they map onto axes discernible in our review of the literature on the media and cultural industries. The discursive placement of social media work and/or workers on these axes is, we contend, useful for understanding mechanisms of visibility, or, alternatively, invisibility (Hatton, 2017).

\section{Findings and Discussion}

\subsection{Visible Brands, Hidden Workers}

Although our interviewees offered a consistent refrain about their jobs, namely that every day is different, many of the responsibilities they explicated-from repackaging news content for Twitter to creating YouTube clips and engaging with audiences on Instagram-were oriented around the axiom of "visibility." Riley, for instance, discussed her reliance on social "analytics to see what stories performed [well]," while Keith noted the importance of quantifiable benchmarks of success: "We also look at link clicks, how many people are reading this, how many comments does the piece have on it right now, how many people shared this post or this story yesterday." To some, like Noemí, the reliance on metrics was a positive element of the job: "It really does provide a lot of insight into what your audience likes, what they don't like, how they might respond to something in the future." Other workers, meanwhile, expressed frustration with senior managers' preoccupation with what Jenna called "vanity metrics," or superficially inflated numbers that provided little insight into consumers' "real" brand engagement. Perhaps not surprisingly, work- ers decried platform changes-most especially unannounced algorithm tweaks - that thwarted their efforts to ensure that content and communication were seen. As Nicole explained of Facebook, "It changes so frequently that it can become somewhat frustrating as a social manager because you might get used to certain content performing well for you and then algorithms change."

Despite-or perhaps because of-social media workers' pursuit of visibility on behalf of their employers' brands, interviewees noted the felt demand to downplay their own visibility. Several of our interviewees thus explained how they concealed their own distinctive communicative styles behind the "voice" of the brand. Riley, for instance, described her job as "being the voice behind the community" (italics added for emphasis), while Olivia described her work as "anonymous in that people don't always know that it's coming from me." Tess, similarly, noted how the ability to conceal her own persona behind the personality of the brand or organization was a key marker of professional potential. "Because I work for a brand, my name isn't attached to anything." Much like those forms of labor that are "hidden" as a result of organizational demands (Weidhaas, 2017), a "good" social media worker is one who can successfully cloak their individual identity behind the veil of a corporate entity.

\subsection{Economic and Social Invisibility}

Crucially, social media work was not only intentionally concealed by employees; it was also, according to interviewees, rendered invisible by both employers and the wider public. Several social media workers indicated their devalued status through expositions of their relatively low compensation, especially compared to careers in Big Tech. Laura noted how social media workers earn "definitely less" than their peers in expressly technical roles, in part because "companies don't totally value their employees." Work, moreover, stretched into all hours of the day-typically without overtime compensation. As Donna explained of the always-on culture, "[I] loved what I was doing... though [I] was not getting paid for all the extra duties I was putting on myself." Melissa, similarly, recounted "get[ting] all of my content scheduled, emails, social....Then I'd say, 'Okay, now I have three free hours, and then I have to do it all again.' There was just no way to really get in front of it. It was brutal."

In other cases, workers noted how their careers were socially devalued, as the public perceived their jobs as frivolous or unchallenging. As Blaire explained, "[People joke]...'Oh, you write tweets for a living.' But people don't realize how much goes into a single tweet." Similarly, Veronica noted, "I think a lot of people think of social media as just an intern sitting on Twitter all day, which is entirely not what I do." Jenna, meanwhile, identified a chasm between the external perception and reality of social media work: "The amount of strategy and planning [required] - I don't think that a lot of people fully 
realize that." She added, "There's always people that are like, 'Oh, just let an intern take care of the social because they know it better than anyone.'" Such repeated invocations of the imagined "intern" - a trope used to signal an oft-exploited worker subjectivity-attest to the lack of status ascribed to those employed in social media as well as to gender and age-based assumptions that reaffirm its invisible status (e.g., Shade \& Jacobson, 2014).

Other interviewees noted how the valuation of this career was bound up with identity-based assumptions about what constitutes a "valuable" worker subjectivity within contemporary organizations. Alice found that many people assumed it was "an easy job...[something meant for] a dumb, 20-year-old girl." In dispelling this assumption, she countered, "It's really hard, and you get no credit and no visibility." Alice also noted how this social devaluation belied the economic import of social media within a digitally driven economy:

If we were only getting like 10 percent of traffic from social media, it wouldn't be that important of a job. When you're getting the majority of it from social media, and posts can live or die based on if it's posted to Facebook and how it's posted to Facebook, that becomes a super valuable skill.

Riley's exposition was remarkably similar: "You have to do the work and strategize so that you... can make your company profitable." As such, she noted, "The work I'm doing isn't for nothing. The work I'm doing isn't just throwing silly captions at the wall and just hoping they stick."

Despite external perceptions of social media work, our interviewees highlighted the time, energy, and emotional labor demands. More pointedly, they detailed how the emotional toll of dealing with online antagonism was largely overlooked by outsiders. "A part of the job people don't think about," Lacie explained, is the incessant exposure to toxicity: "You are on the other end of a public face. And a lot of the time that means routing people to customer service or dealing with trolls or dealing with the fallout when something that you've posted was just a mistake." Donna, similarly, concluded that those aspiring to work in social media should "[recognize] that there are crazy people on the internet." She added, "If that really bothers you, it's gonna be tough to be a social media manager. If you don't have thick skin, it's gonna be tough. You can't take it personally." However, as Riley acknowledged:

You're dealing with trolls all the time on the internet, and you can ignore them all you want but they're still going to impact you. You're going to read a negative comment about something you wrote, and it's going to upset you, but you just have to roll with it.

Notions of "roll[ing] with it" and maintaining a "thick skin" invoke the unpaid, oft-invisible management of emotions that is central to Hochschild's (1983/2012) formulation of emotional labor.

More broadly, and given what interviewees considered a patterned devaluation of their jobs, it seems useful to consider how these positions were rendered more or less visible-and by whom. Such mechanisms of in/visibility emerged along two parallel axestechnical-communication and creation-circulation; as noted above, we deemed these salient given their historical role in the organization of work within the media and cultural industries. As we show, while workers tended to emphasize the former, more valuable dimensions (i.e., technical and creational), they confronted tensions from employers and members of the public who largely associated social media work with the latter (i.e., communication- and circulation-focused).

\subsection{In/Visibility Mechanisms: Technical-Communication Axis}

Social media's placement at the interface of communications and technology has-much like the antecedent industries of telephony (Lipartito, 1994) and computing (Light, 1999) - engendered a highly variable discursive positioning of the work. When discussing their jobs, interviewees emphasized the technical nature of their positions through invocations of data, analytics, and objective calculations. Tess, for instance, described how a social media career allowed her to discover a "right-brained, analytical capacity that I didn't know that I had." Her exposition contrasted sharply with that of Diya, who supplied a metaphor offered by one of her managers about "what social editors do": They are "art-directing every piece of content that goes out there." As Diya's comment suggests, outsiders foregrounded the communications dimension by noting the importance of human expression.

Melissa, meanwhile, drew on her range of experiences working both in and on social media to reflect on the fraught valuation of various careers linked to social media. "The nature of being Big Tech [is that] their bread and butter-their kings of that world-are the engineers." She added, "It's reflected even in the office structure. The engineers have the best seating and the best everything. The marketing and operations teams where I was... weren't regarded in the same way." Here, Melissa indicated what Hatton (2017) has described as the socio-spatial mechanism of invisible labor, which is "devalued because it is physically segregated from a culturally defined worksite" (p. 337). To this end, Jenna explained how the novelty of the profession meant that it could be "housed in different places within different organizations: in some places, it's in marketing, in some places, it's PR. [In other places], it's part of digital."

Other interviewees spoke to this technicalcommunication configuration in addressing the lack of perceived status in the imaginations of both employers and the public. Following the above-mentioned 
discovery of her "right-brained" capacity, Tess told us that she regretted not tapping into this skill set earlier, especially given the broader valuation of technical skills in the contemporary economy. "It's people with STEM backgrounds who end up in these very lucrative fields." She added, "Had I known that as a younger person... that you can use numbers to tell a story just like you can use words, I think that is something that would have opened up professional opportunities like this to me sooner." Much like Alice's comment about the perception that social media is something that any "20-year-old girl can do," Tess, too, noted how the worth of different social media jobs was bound up with a gender-coded division of labor. She thus contrasted the "pink ghetto jobs" of media-where "writers and editors were very replaceable, and [as] such, the salary is very low" - with social media and the "more traditionally male-coded skills attached to it." This suggests that the occupational clusters emerging in social media thus seem to replicate longstanding, and unabashedly gender-coded hierarchies in media and cultural work.

\subsection{In/Visibility Mechanisms: Creation-Circulation Axis}

In chronicling their careers, social media workers invoked a second, seemingly parallel axis, between the production and promotion of media and cultural products. Indeed, social media management oscillates between the poles of creation (writing, recording, editing, or otherwise producing original content) and circulation (distributing and promoting packaged content to digital audiences). These conflicting demands point to a key tension among social media workers: Whereas some felt their employers considered them central-and, thus, valuable-to content development, others detailed how companies seemed to perceive social media work as more akin to public relations. As Alice put it, "It's like someone else does the creative work and then you're selling it." Other interviewees noted how their responsibilities were oriented more clearly toward promotion, rather than production. Whereas Blaire highlighted some collaboration among the social media workers and creative teams at her company, she reaffirmed her role as content circulator: "Now when I do stuff... my day is kind of set for me because, I hate to say it, like it is kind of more robotic almost because you're just pushing out what is being posted on a website usually." Blaire's comment captured a sense of distance from the production processes, as the work of "pushing out" content came after this content had already been assembled. Alice, meanwhile, expressed feelings of removal from the outside; she had hoped to write original articles, but she found that her managers "weren't really that into me writing at the place where I worked because they wanted me to focus on social media."

Such role ambiguity ostensibly led to confusion and, depending on the company, structures of devaluation. For instance, Gracie pointed out that social media work can be misconstrued as non-laborious: "I think social media can be kind of underrated....It can seem easy because you're not the one doing the actual reporting. But you're responsible for communicating the information. You have to have it factually accurate." Gracie's account is, perhaps, a testament to the still-nascent nature of social media as a business priority. Such novelty sustained the misconception that social media work is not as challenging or agentive as "actual reporting." Ellen offered a similar comment and situated her discussion of this work within longstanding gender roles (Daniels, 1987) and more recent observations about occupational segregation in the cultural industries (Hesmondhalgh \& Baker, 2015; Levinson, 2015):

I think also within journalism, social media jobs are the lowest rung on the ladder. We know a lot about what happens when things are gendered as women's work....It seems to me this confluence of maybe it was already gendered, and that's why it's the lowest paid job, or maybe it's a low paid job, and women get stuck there. I don't know. It's a chicken or egg kind of thing. It's the sort of thing, too, that at least within media, if you want to not be writing tweets for your publication, you really have to claw your way out of that position. It's like being branded as a perma-assistant. I think it's quite difficult for people, for women in particular, to take those jobs and transition to a different type of journalistic work, even if they took it with the expectation that it would just be a starting place.

Ellen's use of "stuck" and "perma-assistant," as well as her reference to social media management as "women's work," reaffirms both the limited career trajectories attached to this type of work and its often gender-coded devaluation.

Attuned to these (problematic) perceptions, some interviewees challenged the devalued status of publicity/promotional work. Veronica, for instance, likened her position at a large media publication to "the best seat in the house" because she and her fellow social media workers interacted with "everyone on the floor, from reporters [to] copy editors, designers, [and] video teams." Others articulated how their circulation workeven if not understood as such by their employerscombined creative and promotional processes in manners that lent themselves quite well to other careers. Tess said that she and other social media workers are privy to the interests of digital audiences and are, thus, uniquely positioned to drive production decisions:

I find myself advocating for stories that would otherwise be ignored, because editors think it's like, too mass, or not on-brand, or, you know, "This isn't us." And I say, "Well, it may not be you, but it is millions of people on Facebook, and they deserve to read about stuff that interests them." 
While Tess acknowledged that social media workers are not always "influencing the pieces of journalism that you read," it is important to highlight this influence as a possibility. The productive bent of social media management also materialized in what a few of our interviewees referred to as recirculation, wherein they repackaged and redistributed company assets. Noemí noted that her work entailed searching for social media trends and recirculating content to spark new conversations:

So, that's one of my daily things that I do, is I look to see what's trending on social, in terms of news. What are other outlets talking about? And then from there, if there's something that I feel like we can recirculate with our content, or also share from one of the other... sites, I'll go ahead and do that. So, that's also something that I look at, like what's the longevity of this clip? Is this something that I feel like could potentially be talked about in different ways?

Likewise, Gracie visualized recirculation as a "hamster wheel of creativity" - one that, in her opinion, demands creative and strategic fortitude. As she explained, "You can't really just like rest and stop for a day. You always have to be thinking." While recirculation offers a productive framework for articulating the value of social media work, these tasks, crucially, fail to provide bylines and other visible markers of credit that translate into individual reputational currency (Hearn, 2010).

\section{Conclusion: The Value and Visibility of Digitally Enabled Cultural Work}

In addressing the inequality and precarity structuring the platform labor economy, van Doorn (2017) identified a quandary: "How does one value something one cannot and often does not want to see?" Recent studies of digital labor have captured the extent of this plight, with accounts of the metaphorical "ghosts in the machine" of gig work (Gray \& Suri, 2019), the "behindthe-screen" work of content moderators (Roberts, 2019), and the "hidden and often-stigmatized" labor of online community managers (Nakamura, 2015). Yet the sprawling category of work in social media is somewhat distinctive in that the central aim of this unseen labor is to render an employer hyper-visible. For brands, visibility is tantamount to attention and, presumably, the accrual of value. In this way, social media work is discursively located within a visibility paradox, similar to those observed in studies of surveillance cultures (Anteby \& Chan, 2018), aesthetic labor (Crain et al., 2016; Mears, 2014), and platform-based care work (Mateescu \& Ticona, 2020). What makes this paradox even more pronounced is that it defies the promotional logic of media and cultural workers in the neoliberal digital economy. Individual employability-packaged as a strategic, consistent self-brand-hinges on identifiable authorship and crediting - that is, visibility (Arvidsson et al., 2016;
Duffy, 2017; Gershon, 2017; Jacobson, 2020). But social media work mandates that workers intentionally "hide" their identities and their labor, concealing both as they toil to uphold the "voice of the brand."

While social media work is by definition "hidden" (Weidhaas, 2017), our analysis reveals how it is also rendered invisible-that is, devalued-through the assumptions and practices of both employers and the wider public. The under-compensated nature of this profession is a key index of its economic devaluation. While the media and creative industries have long relied upon the unpaid labor of interns, apprentices, or amateur/hopefuls, interviewees felt that their work failed to draw the financial compensation-or economic visibility-of other positions at the interface of technical and creative skills. At the same time, the $24 / 7$ nature of social media meant that employees were expected to be ever-available to circulate social media content-often without additional remuneration. Our interviewees also noted how their work was socially devalued by employers and, more pointedly, members of the public, who dismissed the work as trivial or thoughtless-both qualities associated with the cultural denigration of feminized work (Duffy \& Schwartz, 2018). In addition, interviewees felt that the emotional laboring requirements were overlooked by outsiders. It is in this vein that cultural critic Ella Dawson (2020) recently compared social media managers to bodyguards: "They take all the hits for your brand, from the abuse of drive-by trolls to meaningful backlash when your company makes a bad decision." Such laboring requirements seem to have intensified in the wake of the global Covid-19 pandemic; journalist Marta Martinez (2020) described how those at the frontlines of corporate Twitter handles and Facebook accounts face grueling demands amid a "relentless news cycle." Moreover, with online hate circulating largely unchecked on these platforms, social media workers are frequent targets of internet users' misdirected ire and antagonism. Despite the "importance of their work," Martinez (2020) noted, it is often "invisible and undermined."

To illuminate the discursive processes of such undermining, we have presented a framework of two axestechnical-communication and creation-circulationwhich function as "mechanisms" (Hatton, 2017) through which work/workers are valued or devalued. These axes are by no means unique to social media; rather, work in the media and cultural industries has long been structured by occupational clusters-many of which are implicated in social valuations of work and workers (Hesmondhalgh \& Baker, 2015). Our research on social media reveals that-much like the earlier fields of telephony (Lipartito, 1994), computing (Light, 1999), film and TV (Mayer, 2014), and journalism (Nilsson, 2010)the value of this work is often shaped by gender-coded assessments and inequities. But while industrial histories furnish insight into the deep-rooted tensions between technology and communication, and between creation and circulation, these associations are by no means 
natural or inevitable. As such, we encourage additional studies of social media work to ensure that, although these workers may remain hidden, the labor accrues the value, status, and renumeration of more visible categories of digital labor.

\section{Acknowledgments}

This project was made possible thanks to grant support from the President's Council of Cornell Women and the Cornell Center for Social Sciences. The authors would also like to express their appreciation to the following for their support and guidance throughout the processes of researching, writing, and revising this manuscript: thematic issue editors Salla-Maaria Laaksonen and Mikko Villi, along with the two anonymous reviewers; members of Cornell's New Media \& Society working group; research assistants John Lunsford, Chris Pardee, and Jillian Singer; and the interview participants who generously shared their insight and experiences.

\section{Conflict of Interests}

The authors declare no conflict of interests.

\section{References}

Abidin, C. (2016). Visibility labour: Engaging with influencers' fashion brands and \#OOTD advertorial campaigns on Instagram. Media International Australia, 161(1), 86-100.

Anteby, M., \& Chan, C. K. (2018). A self-fulfilling cycle of coercive surveillance: Workers' invisibility practices and managerial justification. Organization Science, 29(2), 247-263.

Armstrong, P., Armstrong, H., \& Scott-Dixon, K. (2008). Critical to care: The invisible women in health services. University of Toronto Press.

Arvidsson, A., Gandini, A., \& Bandinelli, C. (2016). Selfbranding among freelance knowledge workers. In $\mathrm{M}$. Crain, W. Poster, \& M. Cherry (Eds.), Invisible labour: Hidden work in the contemporary world (pp. 28-46). University of California Press.

Bagger, C. (2021). Social media and work: A framework of eight intersections. International Journal of Communication, 15, 2027-2046.

Baym, N. (2013). Data not seen: The uses and shortcomings of social media metrics. First Monday, 18(10). https://doi.org/10.5210/fm.v18i10.4873

Bucher, T. (2012). Want to be on the top? Algorithmic power and the threat of invisibility on Facebook. New Media \& Society, 14(7), 1164-1180.

Budd, J. (2016). The eye sees what the mind knows. The conceptual foundations of invisible work. In M. Crain, W. Poster, \& M. Cherry (Eds.), Invisible labour: Hidden work in the contemporary world (pp. 28-46). University of California Press.

Chen, Y. (2016, April 21). “Things don't go viral by them- selves": Inside the social media manager cabal. Digiday. https://digiday.com/marketing/spontaneousplanned-social-media-managers-formed-supportgroup-online

Cherry, M. A. (2016). Virtual work and invisible labor. In M. Crain, W. Poster, \& M. Cherry (Eds.), Invisible labour: Hidden work in the contemporary world (pp. 28-46). University of California Press.

Crain, M., Poster, W., \& Cherry, M. (Eds.). (2016). Invisible labor: Hidden work in the contemporary world. University of California Press.

Daniels, A. K. (1987). Invisible work. Social Problems, 34(5), 403-415.

Dawson, E. [@brosandprose]. (2020, June 16). Social media managers are the digital bodyguards of your company. They take all the hits for your brand, from the abuse [Tweet]. Twitter. https://twitter.com/ brosandprose/status/1272927241702383618

Duffy, B. E. (2017). (Not) getting paid to do what you love: Gender, social media, and aspirational work. Yale University Press.

Duffy, B. E., \& Schwartz, B. (2018). Digital "women's work?": Job recruitment ads and the feminization of social media employment. New Media \& Society, 20(8), 2972-2989.

Duffy, M. (2007). Doing the dirty work: Gender, race, and reproductive labor in historical perspective. Gender \& Society, 21(3), 313-336.

Gershon, I. (2017). Down and out in the new economy. University of Chicago Press.

Gillespie, T. (2018). Custodians of the internet: Platforms, content moderation, and the hidden decisions that shape social media. Yale University Press.

Glaser, B., \& Strauss, A. L. (1967). The discovery of grounded theory: Strategies for qualitative research. Aldine.

Goldhaber, M. H. (1997). The attention economy and the net. First Monday, 2(4). http://firstmonday.org/ article/view/519/440

Gray, F. (Ed.). (2012). Women in journalism at the fin de siècle: Making a name for herself. Springer.

Gray, M. L., \& Suri, S. (2019). Ghost work: How to stop Silicon Valley from building a new global underclass. Eamon Dolan Books.

Hatton, E. (2017). Mechanisms of invisibility: Rethinking the concept of invisible work. Work, Employment and Society, 31(2), 336-351.

Hearn, A. (2010). Structuring feeling: Web 2.0., online ranking and rating, and the digital "reputation" economy. Ephemera, 10(3/4), 421-438.

Hesmondhalgh, D., \& Baker, S. (2015). Sex, gender and work segregation in the cultural industries. The Sociological Review, 63, 23-36.

Hill, E. (2016). Never done: A history of women's work in media production. Rutgers University Press.

Hochschild, A. R. (2012). The managed heart: Commercialization of human feeling. University of California Press. (Original work published 1983) 
Irani, L. (2015). The cultural work of microwork. New Media \& Society, 17(5), 720-739.

Jacobson, J. (2020). You are a brand: Social media managers' personal branding and "the future audience." Journal of Product \& Brand Management, 29(6), 715-727. https://doi.org/10.1108/JPBM-032019-2299

Jarrett, K. (2016). Feminism, labour and digital media: The digital housewife. Routledge.

Levinson, A. L. (2015). The pink ghetto of social media. Medium. https://medium.com/matter/thepink-ghetto-of-social-media-39bf7f2fdbe 1

Light, J. S. (1999). When computers were women. Technology and Culture, 40(3), 455-483.

Lipartito, K. (1994). When women were switches: Technology, work, and gender in the telephone industry, 1890-1920. American Historical Review, 99(4), 1075-1111.

Male journalists dominate the news. (2019, March 25). The Economist. https://www.economist.com/ graphic-detail/2019/03/25/male-journalistsdominate-the-news

Martinez, M. (2020). The social media managers are not okay. Medium. https://onezero.medium.com/thesocial-media-managers-are-not-ok-74bc3d748149

Mateescu, A., \& Ticona, J. (2020). Invisible work, visible workers: Visibility regimes in online platforms for domestic work. In D. Das Acevedo (Ed.), Beyond the algorithm: Qualitative insights for gig work regulation (pp. 57-81). Cambridge University Press.

Mayer, V. (2014). To communicate is human: To chat is female: The feminization of US media work. In C. Carter, L. Steiner, \& L. McLaughlin (Eds.), The Routledge companion to media and gender (pp. 51-60). Routledge.

McCosker, A. (2017). Social media work: Reshaping organisational communications, extracting digital value. Media International Australia, 163(1), 122-136. https://doi.org/10.1177/1329878X17693 702

Mears, A. (2014). Aesthetic labor for the sociologies of work, gender, and beauty. Sociology Compass, 8(12), 1330-1343.

Meisner, C., \& Ledbetter, A. M. (2020). Participatory branding on social media: The affordances of live streaming for creative labor. New Media \& Society. Advance online publication. https://doi.org/ $10.1177 / 1461444820972392$

Nakamura, L. (2015). Afterword: Blaming, shaming, and the feminization of social media. In R. E. Dubrofsky \& S. A. Magnet (Eds.), Feminist surveillance studies (pp. 221-228). Duke University Press. https://www.degruyter.com/document/doi/10.1515/ 9780822375463-015/html

Neff, G. (2012). Venture labor: Work and the burden of risk in innovative industries. MIT Press.

Nilsson, M. L. (2010). "Thinkings" and "doings" of gender: Gendering processes in Swedish television news production. Journalism Practice, 4(1), 1-16.

Poster, W. R. (2016). The virtual receptionist with a human touch: Opposing pressures of digital automation and outsourcing in interactive services. In $\mathrm{M}$. Crain, W. Poster, \& M. Cherry (Eds.), Invisible labour: Hidden work in the contemporary world (pp. 87-112). University of California Press.

Roberts, S. T. (2019). Behind the screen: Content moderation in the shadows of social media. Yale University Press.

Sannon, S., \& Cosley, D. (2019, May 4-9). Privacy, power, and invisible labor on amazon mechanical turk [Paper presentation]. CHI 2019 Conference on Human Factors in Computing Systems, Glasgow, Scotland.

Scolere, L. (2019). Brand yourself, design your future: Portfolio-building in the social media age. New Media \& Society, 21(9), 1891-1909.

Shade, L. R., \& Jacobson, J. (2014). "Give us bread, but give us roses": Gender and labour in the digital economy. International Journal of Media \& Cultural Politics, 10(2), 129-144.

Spencer, K. A. (2017, October 21). The face of the machine: The emotional toll of working in social media. Salon. https://www.salon.com/2017/10/21/ the-face-of-the-machine-the-emotional-toll-ofworking-in-social-media

Star, S. L., \& Strauss, A. (1999). Layers of silence, arenas of voice: The ecology of visible and invisible work. Computer Supported Cooperative Work (CSCW), 8(1), 9-30.

Ticona, J., \& Mateescu, A. (2018). Trusted strangers: Carework platforms' cultural entrepreneurship in the ondemand economy. New Media \& Society, 20(11), 4384-4404.

Troughton, J. (2021). There's a person behind the brand account: Handling situations like the PlayStation stores. The Gamer. https://www.thegamer.com/ person-behind-brand-account-playstation-storessocial-media

Turow, J. (1997). Breaking up America: Advertisers and the new media world. The University of Chicago Press.

Uifalean, A. (2019). How to become a social media manager. Lumen5. https://lumen5.com/learn/socialmedia-manager

van Dijck, J., \& Poell, T. (2013). Understanding social media logic. Media and Communication, 1(1), 2-14.

van Doorn, N. (2017). Platform labor: On the gendered and racialized exploitation of low-income service work in the "on-demand" economy. Information, Communication \& Society, 20(6), 898-914.

Webb, B. (2020, July 13). How social media managers became the fashion frontline. Vogue Business. https://www.voguebusiness.com/companies/ how-social-media-managers-became-the-fashionfrontline

Webster, J. (2014). Shaping women's work: Gender, employment and information technology. Routledge. 
Weidhaas, A. D. (2017). Invisible labor and hidden work. In C. R. Scott \& L. K. Lewis (Eds.), The international encyclopedia of organizational communication (pp. 1-10). Wiley.

\section{About the Authors}

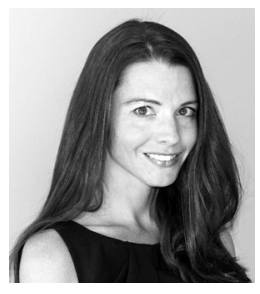

Brooke Erin Duffy (PhD) is an associate professor in the Department of Communication at Cornell University. Her research interests include digital and social media industries; gender, identity, and inequality; and the impact of new technologies on creative work and labor. Her books include (Not) Getting Paid to Do What You Love: Gender, Social Media, and Aspirational Work (Yale University Press, 2017) and Platforms and Cultural Production, with Thomas Poell and David Nieborg (Polity, 2021).

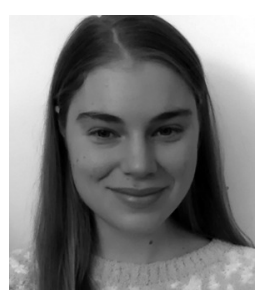

Megan Sawey is a PhD candidate in the Department of Communication at Cornell University. Her research interests include paid companionship practices and new media technologies, platformized creative work and labor, cultural production, identity and labor, and digital feminist resistance. 